

\title{
Impact of retention interval on recognition of a new sensory variant of orange juice
}

Stephanie Chambaron, Pauline de Facq, Xavier Virely, Claire Chabanet, Sylvie Issanchou, Claire Sulmont-Rossé

\section{To cite this version:}

Stephanie Chambaron, Pauline de Facq, Xavier Virely, Claire Chabanet, Sylvie Issanchou, et al.. Impact of retention interval on recognition of a new sensory variant of orange juice. Chemosensory Perception, 2012, 5 (3-4), pp.237-242. 10.1007/s12078-012-9132-x . hal-00939784

\section{HAL Id: hal-00939784 https://hal.science/hal-00939784}

Submitted on 6 Jan 2022

HAL is a multi-disciplinary open access archive for the deposit and dissemination of scientific research documents, whether they are published or not. The documents may come from teaching and research institutions in France or abroad, or from public or private research centers.
L'archive ouverte pluridisciplinaire HAL, est destinée au dépôt et à la diffusion de documents scientifiques de niveau recherche, publiés ou non, émanant des établissements d'enseignement et de recherche français ou étrangers, des laboratoires publics ou privés. 
1 IMPACT OF RETENTION INTERVAL ON RECOGNITION OF A NEW SENSORY

2 VARIANT OF ORANGE JUICE

3 S. Chambaron \& P. De Facq \& X. Virely \& C. Chabanet \& S. Issanchou \& C. Sulmont-Rossé

4 Centre des Sciences du Goût et de l'Alimentation, AgroSup Dijon, CNRS, INRAE, Univ.

5 Bourgogne Franche-Comté, Dijon, France

\section{ABSTRACT}

7 Memory plays a central role in food choice and consumption. Most recent studies focusing on

8 food memory and its role in everyday eating and drinking behaviour used a paradigm

9 developed by Mojet and Köster (2002), based on incidental learning of target foods, and an

10 unexpected memory test, demanding recognition of the target. The present work was an

11 exploratory research and the objective was to study the impact of the retention interval

12 between the learning phase and the recognition phase. Three groups of participants were

13 offered a target orange juice during a first meal organised under a false pretence to ensure

14 incidental learning. Depending on the groups, participants came back one hour, one day or

15 one month later to perform a recognition task: they had to recognize the target orange juice

16 amongst orange juices that differed slightly from the target on sweetness or bitterness. Results

17 showed a rapid decline in recognition performance as the retention interval increased in

18 length. This gradual deterioration of the memory trace over time seems to show that the

19 memory we have of chemosensory stimuli is not particularly resistant.

\section{KEY WORDS}

21 Food, Memory, Implicit learning, Recognition. 


\section{INTRODUCTION}

2 Today, there is a great deal of food products on the market based on a huge range of different

3 recipes. However, upon closer examination it becomes apparent that often, within a given

4 product category, any differences derive from subtle sensory modifications. As such, it is

5 worth looking into what consumers really "retain" about the products they eat and drink. For

6 instance, if consumers are offered an orange juice that is slightly different in sensory terms

7 from the juice they usually drink, will they be capable of memorising it or, a contrario

8 recognizing new variations?

9 Memory seems to be a central element that impacts consumer's food choices and 10 consumption (Laureati, Pagliarini, Mojet \& Köster, 2010). Indeed, consumers make their 11 choices not only on the basis of their perception but also on the basis of the memory of the food they have previously consumed (Köster, 2003). Consequently, studying food memory appears to be an important point to better understand food choices mechanisms. To date, a paradigm suggested by Köster and his colleagues (Mojet \& Köster, 2002; 2005; Köster, Prescott and Köster, 2004) provides a useful tool in the study of food memory in conditions relatively close to those occuring in daily life. Such paradigm consists in presenting participants with target foods during a meal held in the laboratory under conditions allowing an incidental learning of the targets. After a certain retention interval, participants returned to

19 the laboratory where they were unexpectedly asked to perform a recognition test. During this 20 test, they had to recognize the previously consumed targets amongst distractors, which 21 deviated slightly from the target on controlled sensory features (e.g. on flavor). The crucial feature of the implicit paradigm is that participants are not asked to memorize anything and that, under a false pretence, they are invited to have a meal. Thus, memory is never mentioned 24 and incidental learning of the food characteristics is ensured. 
1 Recently, Morin-Audebrand, Mojet, Chabanet, Issanchou, Møller, Köster and Sulmont-Rossé,

22012 used this paradigm and they present a systematic and homogeneous analysis of the

3 merged data from 6 studies with the new paradigm, in order to extract some 'general

4 characteristics' of food memory. The use of this paradigm highlights some properties of

5 sensory memory that come into play when a food is eaten. Specifically, food memory seems

6 more effective in detecting sensory modifications in a product that has already been tasted,

7 than in identifying the similarity between one food and another eaten earlier (Morin-

8 Audebrand et al., 2012). Moreover, in this study, the authors also investigated the impact of

9 retention interval (i.e the impact of the length of time separating the learning phase and the

10 test phase) by re-analysing data providing of different studies. Unfortunately, this study does

11 not show an impact of retention interval on recognition performance. However, this result

12 should be taken with caution as the impact of retention interval was evaluated by comparing

13 different studies, conducted with different products.

14 The present work was an exploratory research and its aim was to explore the impact the

15 retention interval. In fact, this experimental factor varied from 8 hours to 7 days in the Morin-

16 Audebrand et al.'s paper but the impact of this factor was not explored as it varied across

17 different experiments. Going over the literature, we noted that the effect of the retention 18 interval has been studied very little with chemosensory stimuli, whereas it has been well 19 documented with other stimuli (Schacter, 1987, Tulving \& Schacter 1990).

\section{MATERIALS AND METHODS}

\section{Overview}

22 Three groups of consumers $(\mathrm{N}=91)$ were recruited ("+ 1 hour" group: 22 women / 8 men, average age 25.0 years old; "+1 day" group: 18 women / 12 men, average age 24.7 years old; 
1 "+1 month" group: 24 women / 7 men, average age 22.9 years old). They were randomly

2 divided into three groups:

3 - The " +1 hour" group $(\mathrm{N}=30)$ : the learning session and the test session were separated by a time interval of one hour.

- $\quad$ The "+1 day" group ( $\mathrm{N}=30)$ : the learning session and the test session were separated by a time interval of one day.

- The "+1 month" group $(\mathrm{N}=31)$ : the learning session and the test session were separated by a time interval of one month.

\section{Participants}

10 To participate, the candidates must not previously have participated in a study on memory. They had to be aged between 18 and 35 and be consumers of the model (orange juice). The experimental protocol was approved by the Comité de la Protection de la Personne (Ethical Research Committee) Est I of Dijon. In accordance with the procedures of this regulatory body, the participants received written and oral information on the study before signing a consent form. In return for their participation, they received $20 €$ in the form of vouchers.

\section{Products}

17 The evaluation of sensory memory according to retention interval was carried out using a 18 pulp-free orange juice (Joker@). Five variants were prepared from this orange juice: a "target" orange juice and four "distractor" orange juices (Table 1). The target orange juice was prepared by increasing the concentration of sucrose and quinine in the basic orange juice. To avoid having a target product perceived as overly sweet, the added sucrose was offset by the addition of citric acid to the proportion of $40 \mathrm{mg} / \mathrm{L}$ (see Keast \& Breslin, 2003 and Delwiche,

232004 for a detailed review of flavour-flavour interactions). The aim was to have a target orange juice with a different flavour from the commercial product, on the one hand to avoid a 
1 familiarisation effect with the commercial product interfering with participants' performance

2 and, on the other hand, so that we could prepare variants that were less sweet and less bitter

3 than the target. The distractors were prepared by modifying the concentration of sucrose or

4 quinine in order to create an intensity of sweetness or bitterness 2.5 times the Difference

5 Threshold (DT) lower or higher than the intensity of sweetness or bitterness of the target

6 variant. The Difference Threshold (DT) is defined as the smallest difference between two

7 physical values (here, two concentrations) giving rise to a difference in intensity perceived by

$850 \%$ of the population. These difference thresholds (sucrose: $1 \mathrm{DT}=10 \mathrm{~g} / \mathrm{L}$; hydrochloride

9 quinine: $1 \mathrm{DT}=9 \mathrm{mg} / \mathrm{L}$ ) were determined through a preliminary experiment run with 16

10 participants different from those who took part in the main study (see Köster et al., 2004, for

11 an exhaustive account of this procedure).

12 Table 1. For each variant, quantity of sucrose, hydrochloride quinine added in the finished 13 product

\begin{tabular}{lll}
\hline & Sucrose $(\mathrm{g} / \mathrm{L})$ & Quinine $(\mathrm{mg} / \mathrm{L})$ \\
\hline Target & 30 & 25 \\
-2.5 DT sugar & 5 & 25 \\
+2.5 DT sugar & 55 & 25 \\
-2.5 DT bitter & 30 & 2.5 \\
+2.5 DT bitter & 30 & 47.5 \\
\hline
\end{tabular}

\section{Procedure}

16 The subjects participated in two sessions with a well-defined time interval between each. Both 17 sessions began at 7.15 a.m. The first session - the learning phase - lasted 30 minutes and the 18 second test session lasted an hour. As described in the overview, participants were randomly divided into three groups: "+1 hour" group, "+1 day" group and "+1 month". 


\section{Session 1: Learning phase}

2 For the first session, the participants were asked to come to the sensory evaluation room at

3 INRA on an empty stomach, under the false pretence of studying the development of the

4 sensation of hunger after breakfast. After answering a few questions on their sensation of

5 hunger, the subjects were given a breakfast made up of a glass of target orange juice (150 ml),

6 a sweetened plain yoghurt (Paturage $($ ) $)$ and two slices of brioche (Pasquier@). This breakfast

7 was presented to the participants as being carefully proportioned in terms of calories and they

8 were asked, wherever possible, to finish the portions served to them. After eating their

9 breakfast and answering questions regarding their sensation of hunger, the participants left the room. Then, they had to answer the same questions half an hour and 1 hour after the breakfast

11 ("+1 hour" group), or every hour until lunchtime ("+1 day" and "+1 month" groups). The aim of the false pretence was to avoid focusing the participants' attention on the target orange juice, thereby allowing an incidental (implicit) learning of its sensory characteristics.

\section{Session 2: Test phase}

During this second session, the participants completed a recognition test followed by a discrimination test.

Recognition test. The participants received a series of eight samples of coded orange juice (20 mL per sample): four samples identical to that served during the first session (target orange juice) and four different samples (one sample of each distractor orange juice). After tasting each sample, the participants had to indicate whether the juice was identical to or different from the one they drank at the first session.

Discrimination test. The participants received eight samples of orange juice $(20 \mathrm{~mL}$ per sample): four samples identical to the target orange juice and four different samples (one sample of each distractor orange juice). The participants were also given a glass of target orange juice $(150 \mathrm{~mL})$ as a reference, which they could taste as many times as they wanted in 
1 order to compare it to the coded samples. After tasting each coded sample, the participants

2 had to indicate whether the juice was identical to or different from the reference.

The order of presentation of the samples was different from one subject to the next and,

4 for a given subject, from one test to the next. Thirty-one different orders were randomly

5 selected within the following constraints: 1) no more than 3 target samples or 3 distractor

6 samples in a row; 2) about as many orders beginning with a target as orders beginning with a

7 distractor; 3) as many targets or distractors at each position over the whole series of orders.

8 Each order was assigned to one subject from the "+1 hour group", one subject from the "+1

9 day" group and one subject from the "+1 month" group. The samples were coded by 3-digit

10 numbers randomly drawn. After each sample, the participants had a 30-second break and

11 rinsed their mouth with Evian(c) water.

12

13

14

15

\section{Experimental conditions}

The sessions took place in an air-conditioned, ventilated sensory evaluation room, equipped with individual booths and under white light (AFNOR, 1987). The recognition and discrimination tests were carried out using FIZZ@ software (Biosystèmes, Couternon, France), allowing the answers to be collected automatically. The orange juice samples were poured one hour before each session, then stored at $12^{\circ} \mathrm{C}$. They were served to the participants at this temperature.

\section{Data analysis}

Statistical analyses were conducted using the SAS/STAT® version 9.1 statistical software package (SAS Institute, Cary, NC). All the analyses of variance (ANOVA) were performed with the general linear model procedure of SAS. All results reported here were significant at the 0.05 level unless otherwise noted. Means $(M)$ are given with their standard error $(S E)$. 
The answers obtained in the recognition and discrimination tests were classified under

2 four categories, namely: hits $(\mathrm{H})$ (response: "identical" to a target sample), misses (M)

3 (response: "different" to a target sample), false alarms (FA) (response: "identical" to a

4 distractor sample), and correct rejections (CR) (response: "different" to a distractor sample).

5 According to the Signal Detection Theory (MacMillan \& Creelman, 2005), participant's

6 ability to recognise targets from distractors is assessed independently of response bias, by

7 calculating a recognition index. This index is based on comparing the frequency of hits with

8 the frequency of false alarms: if the subject replied "identical" more often for targets than for

9 distractors, then it may be concluded that the subject did indeed recognise the target amongst

10 the distractors. A second index assesses participant's tilt towards one response or the other by

11 comparing the frequency of "identical" responses and the frequency of "different" responses

12 (response bias). If a participant answered "different" significantly more often than "identical",

13 one might conclude that the participant had a bias towards answering "different" when

14 uncertain about the class of items to which stimuli belong. Although the recognition index $d$ '

15 and bias index $C$ - which require probit transformation of the response proportions - are most

16 widely used, these are less appropriate for use with small sets of stimuli in which proportions

17 of 0 and 1 occur frequently. Therefore, as described in Morin-Audebrand et al. (2012), an empirical logit transformation (Cox, 1970) was used to deal with extreme proportions:

$d_{a}=$ Empirical logit $\left(\mathrm{F}_{\mathrm{H}} \mid\right.$ Target $)-\left(\mathrm{F}_{\mathrm{FA}} \mid\right.$ Distractor $)$

which corresponds to: $d_{a}=\log \left[\left(\mathrm{N}_{\mathrm{H}}+0.5\right) /\left(\mathrm{N}_{\mathrm{M}}+0.5\right)\right]-\log \left[\left(\mathrm{N}_{\mathrm{FA}}+0.5\right) /\left(\mathrm{N}_{\mathrm{CR}}+0.5\right)\right]$

$C a=$ Empirical logit $\left(\mathrm{F}_{(\mathrm{H}+\mathrm{FA})}\right)$

which corresponds to $\mathrm{Ca}=-\log \left[\left(\mathrm{N}_{\mathrm{H}}+\mathrm{N}_{\mathrm{FA}}+0.5\right) /\left(\mathrm{N}_{\mathrm{M}}+\mathrm{N}_{\mathrm{CR}}+0.5\right)\right]$

with $\mathrm{N}_{\mathrm{H}}, \mathrm{N}_{\mathrm{M}}, \mathrm{N}_{\mathrm{FA}}$ and $\mathrm{N}_{\mathrm{CR}}$ corresponding respectively to the number of hits, misses, false

24 alarms and correct rejections. The indices $d_{a}, \mathrm{Ca}$ and the frequencies of hits and false alarms 
1 were determined for each test and each participant. With four target samples and four

2 distractor samples, the higher index $d_{a}$ that could be obtained is equal to 1.91 , which

3 corresponds to perfect recognition (4 hits and 4 correct rejections).

\section{$4 \quad$ RESULTS}

5 For the discrimination test, Student's $t$ tests of the index $d_{a}$ showed that the participants of

6 three experimental groups distinguished the target samples from the distractor samples above

7 the level of chance: for the "+1 hour" group: $t_{(29)}=3.90 ; p<0.001$; for the "+1 day" group:

$8 t_{(29)}=4.26 ; p<0.001$ and for the "+1 month" group: $\left.t_{(30)}=3.54 ; p<0.001\right)$ (cf. Figure 1). One-

9 way ANOVA did not reveal any group effect, either on the index $d_{a}\left(F_{(2.88)}=0.01 ; M S e=2.06\right.$;

$10 p>0.05)$, or on the frequency of hits $\left(F_{(2.88)}=0,21 ; M S e=0.07 ; p>0.05\right)$, or on the frequency of

11 false alarms $\left(F_{(2.88)}=0.19 ; M S e=0.04 ; p>0.05\right)$. Thus, the participants of three groups were capable of discriminating the targets from the distractors during the discrimination test. As such, we can be sure that any difference between groups that might be observed in the recognition test cannot be attributed to a difference in ability to discriminate between samples.

Figure 1. Index of performance in the discrimination test according to retention interval (error bars represent standard error of the mean).

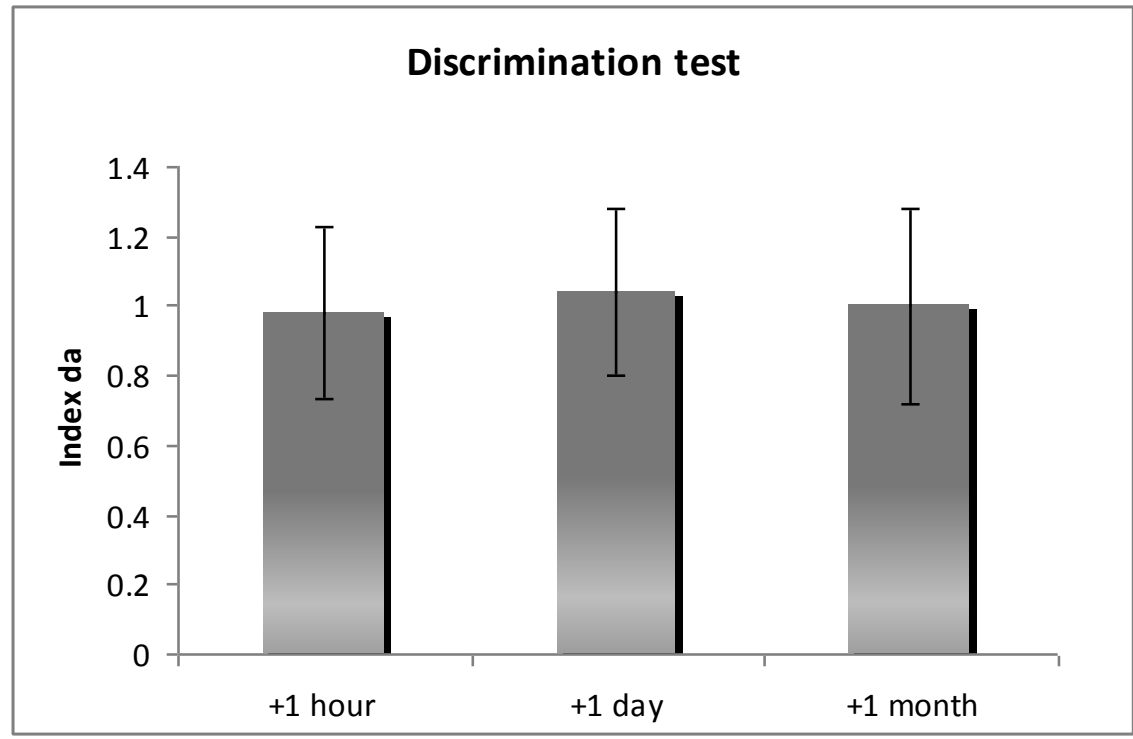


1 Figure 2. Index of performance in the recognition test according to retention interval (error

2 bars represent standard error of the mean).

3

4

5

6

7

8

9

10

11

12

13

14

15

16

17

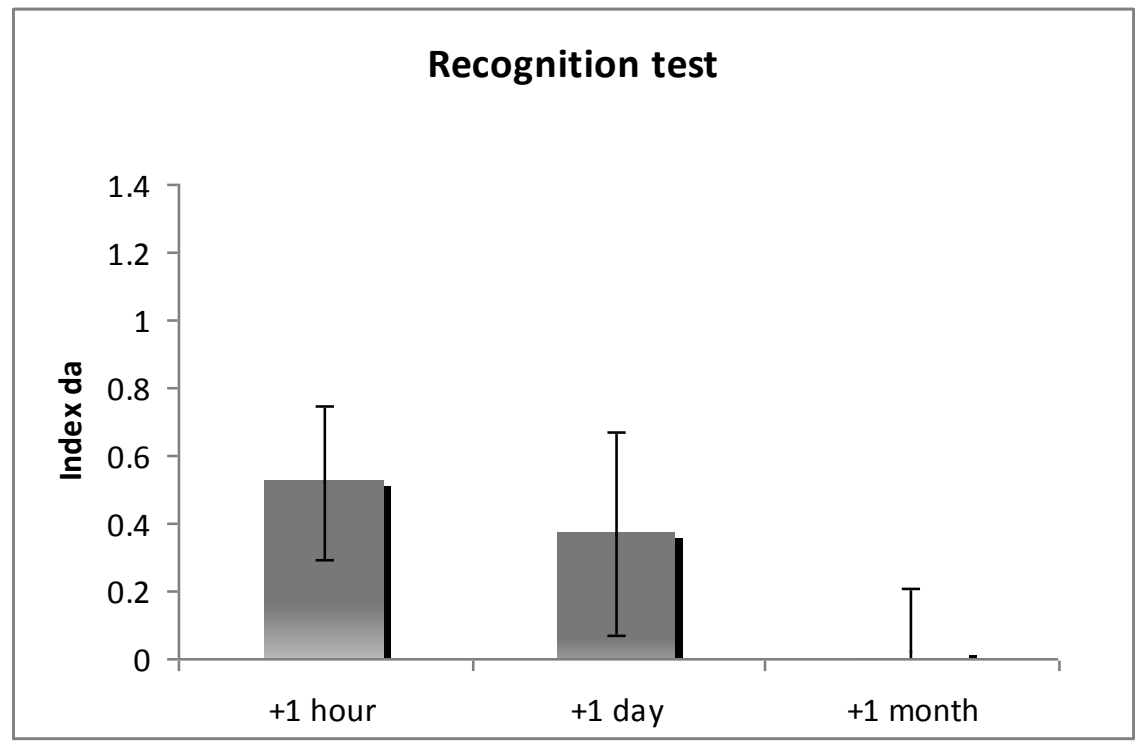

For the recognition test, Figure 2 shows that the longer the retention interval, the less able participants were to recognise the target orange juice from amongst the distractors. Student's $t$ tests of the index $d_{a}$ showed that only the participants in the "+1 hour" group had recognised the target samples amongst the distractor samples above the level of chance: for the "+1 hour" group: $t_{(29)}=2.23 ; p<0.05$; for the "+1 day" group: $t_{(29)}=1.24 ; p>0.05$ and for the "+1 month" group: $t_{(30)}=0.12 ; p>0.05$ ) (cf. Figure 2). Student's $t$ tests of index $C a$ showed that the participants of each group had a bias towards answering "different" ("+1 hour" group $M=0.38, S E=0.13, \mathrm{t}_{(29)}=2.98 \mathrm{P}<0.01 ; "+1$ day" group $M=0.45, S E=0.15, \mathrm{t}_{(29)}=2.98 \mathrm{P}<0.01 ;$ "+1 month" group $\left.M=0.45, S E=0.13, \mathrm{t}_{(30)}=3.49 \mathrm{P}<0.001\right)$. Nevertheless, a one-way ANOVA did not reveal any group effect, either on the index $d_{a}\left(F_{(2.88)}=1.11 ; M S e=1.80 ; p>0.05\right)$, or on the index $C a\left(F_{(2.88)}=0.09 ; M S e=0.55 ; p>0.05\right)$. The frequency of hits and the frequency of correct rejections did not differ between the three groups $\left(F_{(2.88)}=0.74 ; M S e=0.07 ; p>0.05\right.$ $F_{(2.88)}=0.28 ; M S e=0.04 ; p>0.05$, respectively) (Figure 3). It must be underlined that the frequency of hits was lower than would be obtained by chance guessing $(M=0.44 ; S E=0.03)$, 
1 whereas the proportion of correct rejections was higher than chance guessing $(M=0.64$;

$2 S E=0.02)$.

3 Finally, table 2 shows the proportions of correct rejections obtained by the three groups of

4 participants according to the type of distractor. A chi-square test was performed per group

$5 \quad\left(\mathrm{H}_{0}\right.$ : for a given group, no difference between the distributions observed for each distractor)

6 and another per distractor $\left(\mathrm{H}_{0}\right.$ : for a given distractor, no difference between the distributions

7 observed for each group). No difference was observed between the distributions of correct

8 rejections for the different distractors, whatever the group.

9 Figure 3. Proportions of Hits, False Alarms and Correct Rejection. Bars indicate 95\% 10 confidence intervals.

11

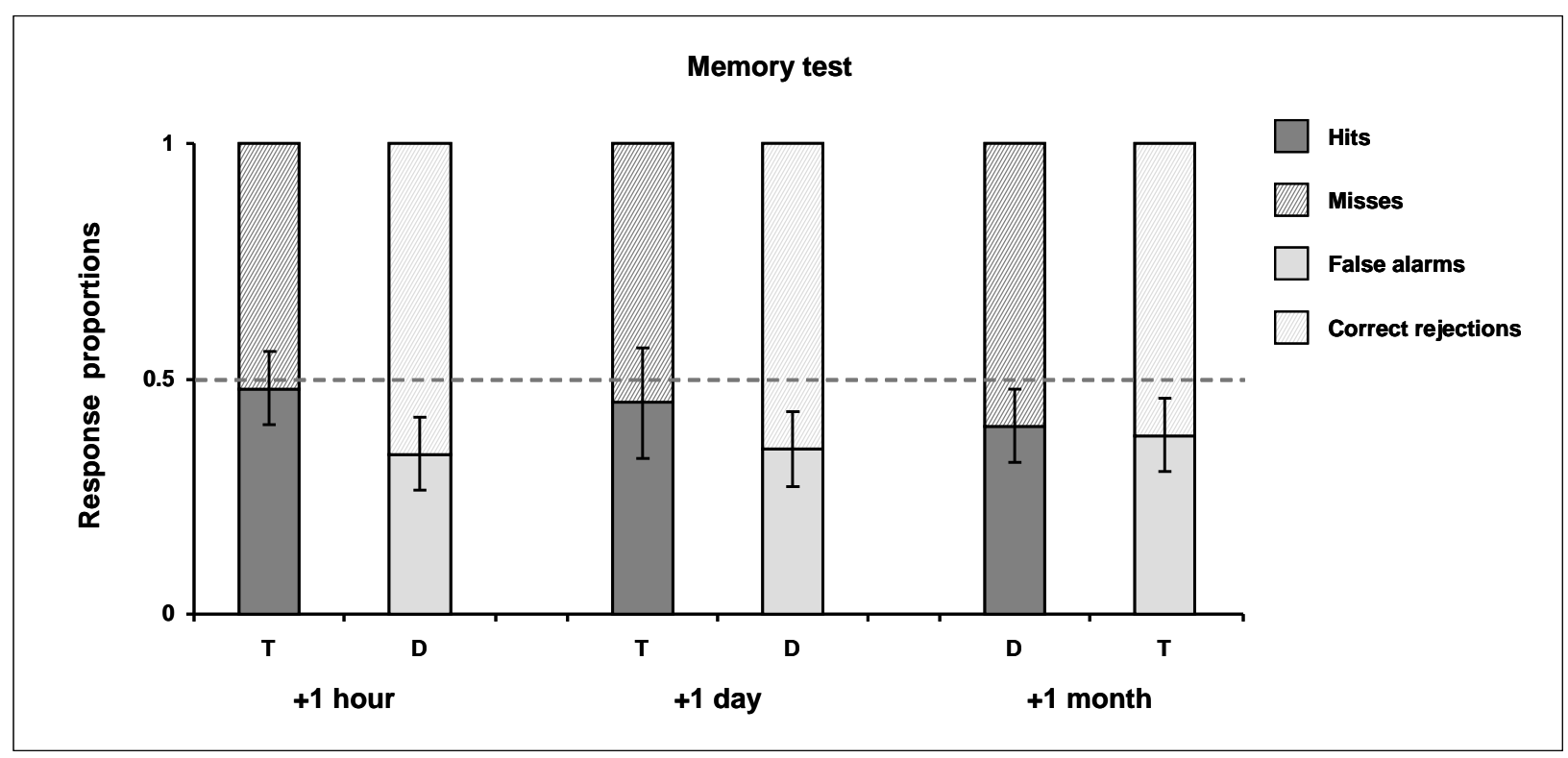


1 Table 2. Proportions of correct rejections (CR) in the three conditions according to the

2 distractor (P values of the Chi-2 tests are given into brackets).

\begin{tabular}{llllll}
\hline \multicolumn{5}{c}{ Distractors } \\
\hline $\begin{array}{llllll}\text { Retention } \\
\text { interval }\end{array}$ & $\mathbf{- 2 . 5}$ SD sugar & $\mathbf{+ 2 . 5}$ SD sugar & $\mathbf{- 2 . 5}$ SD bitter & $\mathbf{+ 2 . 5}$ SD bitter & Chi-2 \\
\hline$+\mathbf{1}$ Hour & 0.63 & 0.70 & 0.60 & 0.70 & $1.00(\mathrm{p}=0.80)$ \\
$\mathbf{+ 1}$ Day & 0.67 & 0.60 & 0.67 & 0.67 & $0.44(\mathrm{p}=0.93)$ \\
$\mathbf{+ 1}$ Month & 0.52 & 0.71 & 0.58 & 0.68 & $3.12(\mathrm{p}=0.37)$ \\
$\mathbf{C h i - 2}$ & $1.60(\mathrm{p}=0.45)$ & $1.01(\mathrm{p}=0.60)$ & $0.52(\mathrm{p}=0.77)$ & $0.08(\mathrm{p}=0.96)$ &
\end{tabular}

\section{DISCUSSION}

4 Our study aimed to investigate the effect of the retention interval on memorisation of an

5 orange juice consumed previously. We explored if a memory trace concerning a

6 chemosensory stimulus learned incidentally can last over time. Our main results showed a

7 rapid decline in recognition performance with the increasing length of the retention interval.

8 We can argue that during the implicit learning phase, participants do not focus enough

9 attention on the product. Consequently, it is very difficult for us to recognize this product

10 among distractors after a retention interval of one day. As the memory trace is not robust,

11 various theories can be advanced to explain this phenomenon of forgetting. According the

12 trace decay theory (Brown, 1958; Peterson \& Peterson, 1959), the passage of time erodes the

13 trace, leading to increasingly difficult retrieval of the initial information. According to

14 interference theory (Underwood, 1957), information is forgotten because another piece of

15 information (often similar) hampers its retrieval. In retroactive interference, new information

16 tends to erase older information. Inversely, with proactive interference, older memories

17 prevail over more recent memories. For both of these theories, "forgetting" does not mean the

18 disappearance of information, but its momentary inaccessibility caused by a variety of 
1 reasons: degradation of the memory trace, reorganization of the material learned, interference

2 or inappropriate retrieval cues (Tiberghien, 1991; Baddeley, 1992).

3 Finally, this experiment confirms a result that has been consistently observed in all

4 experiments using Köster's paradigm (Morin-Audebrand, Mojet, Chabanet, Issanchou,

5 Møller, Köster and Sulmont-Rossé, 2012). When performing a food recognition task,

6 participants showed a strong tendency to give "different" responses, whatever the actual

7 nature of the sample. Such behaviour is reflected in the pattern of recognition responses, with

8 a memory effect that appears to depend more on distractor rejection than on target

9 recognition. Morin-Audebrand et al. (2012) argued that novelty detection is probably a

10 predominant mechanism in incidentally learned memory, as an efficient warning system that

11 immediately reacts to novel information. It seems that participants rely on the feeling that

12 they "have not previously experienced" a sample to make their memory judgments (Köster et 13 al., 2004).

\section{CONCLUSION}

15 To conclude, the results of our study showed that a single exposure to a specific variant of a 16 common food product, under learning conditions similar to incidental exposure in daily life, is 17 not enough to guarantee long-term memorisation of the product. These results seem to challenge a property often associated with the memory we have of chemosensory stimuli, particularly the memory of odours: namely, a remarkable resistance to forgetting and to retroactive interference (Herz and Engen, 1996). It appears that under conditions in which

21 interference is manifest, the memory that we have of chemosensory stimuli is not so resistant 22 to forgetting. It is clear that our results would need to be confirmed with other food products. 23 In the present experiment distractors were obtained by varying the concentration of one 24 ingredient in the target, which means that we had quantitative variation of sensory attributes. 
1 It would also be worthy to examine if similar results will be obtained with new products, less

2 familiar, and also with distractors varying in quality (e.g. by adding a new flavour not present 3 in the target) as Morin-Audebrand et al. (2012), noted that qualitative changes are more

4 correctly rejected than quantitative changes with one-day retention interval.

\section{BIBLIOGRAPHY}

6 AFNOR (1987) Directives générales pour l'implantation de locaux destinés à l'analyse sensorielle. AFNOR, 7 Paris.

8 Baddeley A (1992) La mémoire humaine : théorie et pratique. Presses Universitaires de Grenoble, Grenoble.

9 Brown J (1958) Some tests of the decay theory of immediate memory. Quarterly Journal of Experimental 10 Psychology 10: 12-21.

11 Cox DR (1970) The analysis of binary data. Methuen, London.

12 Delwiche J (2004) The impact of perceptual interactions on perceived flavor. Food Quality and Preference 15: $13 \quad 137-146$

14 Herz RS, Engen T (1996) Odor memory: Review and analysis. Psychonomic Bulletin \& Review 3: 300-313.

15 Keast R, Breslin PA (2003) An Overview of Binary Taste-Taste Interactions. Food Quality and Preference 14: $16 \quad 111-124$

17 Köster EP (2003) The psychology of food choice: Some often encountered fallacies. Food Quality and 18 Preference 14: 359-373.

19 Köster MA, Prescott J, Köster EP (2004) Incidental learning and memory for three basic tastes in food. Chemical 20 Senses 29: 441-453.

21 Laureati M, Pagliarini E, Mojet J, Köster EP (2011) Incidental learning and memory for food varied in sweet taste in children. Food Quality and Preference $22: 264-270$.

23 Macmillan NA, Creelman CD (2005) Detection Theory: a user's guide. Cambridge University Press, New York.

24 Mojet J, Koster EP (2005) Sensory memory and food texture. Food Quality and Preference 16: 251-266.

25 Mojet J, Köster EP (2002) Texture and flavour memory in foods: An incidental learning experiment. Appetite 26 38: 110-117. 
1 Morin-Audebrand L, Mojet J, Chabanet C, Issanchou S, Møller P, Köster E, Sulmont-Rossé C (2012) The role 2 of novelty detection in food memory. Acta Psychologica 139: 233-238.

3 Peterson LR, Peterson MJ (1959) Short-term retention of individual verbal items. Journal of Experimental $4 \quad$ Psychology 58: 193-198.

5 Schacter DL (1987) Implicit memory: history and current status. Journal of Experimental Psychology: Learning, 6 Memory, and Cognition 13: 501-518.

7 Tiberghien G (1991) Psychologie de la mémoire humaine. PUG, Grenoble.

8 Tulving, E., Schacter, D. L. 1990. Priming and human memory systems. Science 247: 301-6

9 Underwood BJ (1957) Interference and forgetting. Psychological Review 64: 49-60. 